\title{
Moral Migration:
}

\section{Desires to Become More Empathic Predict Changes in Moral Foundations}

\author{
Ivar R. Hannikainen ${ }^{1}$, Nathan W. Hudson ${ }^{2}$, William J. Chopik ${ }^{3}$, Daniel A. Briley ${ }^{4} \&$ Jaime \\ Derringer $^{4}$ \\ ${ }^{1}$ UNIVERSIDAD DE GRANADA \\ ${ }^{2}$ SOUTHERN METHODIST UNIVERSITY \\ ${ }^{3}$ Michigan State University \\ ${ }^{4}$ UNIVERSITY OF ILLINOIS AT URBANA-CHAMPAIGN
}

Many people want to change their personality traits-and research on volitional change has documented their success in doing so. In the present study, we examine whether people also wish to change their levels of empathy, and whether these desires precede shifts in dispositional empathy and morality over a 15-week period. We recorded participants' change goals, followed by weekly measurements of empathic concern and perspective-taking, as well as moral foundations. Results indicated that most participants wished to cultivate empathic concern and, especially, perspectivetaking. Those who sought to develop these qualities tended to actually do so at a faster rate than their peers who did not-and, as a consequence, also drifted toward a characteristically liberal, individualizing morality.

Keywords: volitional change, empathy, moral foundations, adult personality development.

Correspondence concerning this article should be addressed to Ivar R. Hannikainen, Department of Philosophy I, Faculty of Psychology, Cartuja Campus, Granada (Spain), 18011. Contact: $\underline{\text { ivar@ugr.es }}$

Word count (excluding abstract, tables and references): 5470 


\section{Moral Migration: Desires to Become More Empathic Predict Changes in Moral Foundations}

A burgeoning literature on volitional change has shown that people also want to change their personality traits (Baranski, Morse, \& Dunlop, 2017; Hudson \& Roberts, 2014; Miller, Baranski, Dunlop, \& Ozer, 2019; Robinson, Noftle, Guo, Asadi, \& Zhang, 2015) and attachment styles (Hudson, Chopik, \& Briley, 2020) for the better. For instance, many adults want to become more conscientious and emotionally stable (Hudson \& Fraley, 2016). Moreover, longitudinal evidence suggests that they often succeed - though change can be slow (Hudson \& Fraley, 2015; Hudson, Fraley, Briley, \& Chopik, 2020) and requires engaging in concrete initiatives (e.g., making weekly plans to pull one's behavior into alignment with desired traits; Hudson, Briley, Chopik, \& Derringer, 2019; also see Hennecke, Bleidorn, Denissen, \& Wood, 2014; Magidson, Roberts, ColladoRodriguez, \& Lejuez, 2014; Roberts, 2018). Thus, volitional change processes mirror sophisticated models developed by health psychologists to characterize the stages that people must advance through to improve their health behavior: from recognizing a problem, to executing a plan to change, and avoiding relapse (e.g., Prochaska, DiClemente \& Norcross, 1993).

Previous studies of volitional change have focused primarily on the big five personality traits and adult attachment styles. However, scholars have also begun to examine whether people want to volitionally change other traits, as well. For example, at least one study asked whether people also wish to become morally better (Sun \& Goodwin, 2020). In that study, comparing morally relevant traits (such as honesty and fairness) to predominantly non-moral traits (such as anxiety and productivity), people showed weaker desires to seek moral improvement compared to non-moral improvement for both themselves and close others.

Despite the fact that people may have lesser desires to increase in morally-relevant traits than other types of traits (Sun \& Goodwin, 2020), adults' moral values have been shown to fluctuate over time (Hatemi, Crabtree, \& Smith, 2019) and to generally follow a particular normative trajectory (Colby et al., 1983; Eisenberg, Miller, Shell, McNalley, \& Shea, 1991). This raises the question of whether these patterns of moral migration might stem from people's desires and attempts to change other personality traits.

In the present work, we draw attention to one particular change goal that could plausibly instigate moral growth: the desire to become more empathic. The notion that moral judgment is dominated by affective processes is among the most widely touted ideas in moral psychology (Haidt, 2007). For example, abnormally low empathy helps explain the immoral conduct of psychopaths (Decety, Chen, Harenski, \& Kiehl, 2013)—while unusually intense empathy often characterizes the 
altruism of moral exemplars (Marsh et al., 2014). Furthermore, research has shown that empathy is relatively malleable (Weisz \& Zaki, 2018): People who believe they can regulate the scope of their empathy expend greater effort to change in this regard (Schumann, Zaki, \& Dweck, 2014). Taken together, these prior findings inspire one of the guiding hypotheses in our present work: that changes in people's moral outlook could result-not expressly from goals to become morally better-but primarily from changes in interpersonal affect (i.e., empathy).

Thus, the present study focused on answering several questions. Do most people aspire to become more empathic? If so, what are the consequences of wanting to, and ultimately succeeding in our efforts to develop greater empathy? If people who cultivate empathy can enjoy some degree of success in doing so, do such volitional changes have any downstream implications for their moral outlook? The present research constitutes an early step in our understanding of these questions. ${ }^{1}$

\section{Development of Empathy}

Empathy can be understood as the tendency to be psychologically in tune with others' feelings and perspectives (Decety \& Lamm, 2006). Although this core disposition is observable already in two year olds (Vaish, Carpenter, \& Tomasello, 2009), the ability to empathize with others continues to develop throughout adolescence (Eisenberg, Cumberland, Guthrie, Murphy, \& Shepard, 2005) and into adulthood (O’Brien, Konrath, Grühn, \& Hagen, 2013; Oh, Chopik, Konrath, \& Grimm, 2019), and also undergirds a wide range of prosocial outcomes (Batson, 2011; Eisenberg et al., 2005; Gleichgerrcht \& Young, 2013).

Most research on the psychological basis of empathy distinguishes at least two facets: empathic concern and perspective-taking. Empathic concern refers to the tendency to feel concern and compassion for others and promotes core demonstrations of moral competence-including cooperation (Preston \& de Waal, 2002) and the acquisition of moral norms (Blair, 1995; Cushman, 2013), such as the opposition to harmful acts (Gleichgerrcht \& Young, 2013) and the duty to help others in need (Batson, 2011). Meanwhile, perspective-taking refers to the tendency to imagine viewpoints different than one's own. Actively simulating another's perspective intensifies empathic reactions to their perceived suffering, over and above merely imagining their feelings (Lamm, Porges, Cacioppo \& Decety, 2008). Such exercises in perspective-taking have been shown to encourage altruism (Batson, Early \& Salvarani, 1997) and suppress negative stereotypes (Galinsky \& Moskowitz, 2000), including racial bias (Todd, Bodenhausen, Richeson, \& Galinsky, 2011).

\footnotetext{
${ }^{1}$ This study was not pre-registered.
} 
Some research calls into question the conceptualization of empathic concern and perspectivetaking as simple continua. For example, some individuals (i.e., psychopaths) do not spontaneously empathize with the same ease as others, but they are able to feel comparable empathy when following concrete instructions (Meffert, Gazzola, den Boer, Bartels, \& Keysers, 2013). This phenomenon implies some dissociation between a person's capacity to feel empathy and their propensity to feel it spontaneously (Keysers \& Gazzola, 2014).

Similarly, highly empathic people can nevertheless display a certain callousness toward dissimilar (Mitchell, Macrae, \& Banaji, 2006) or distant (Slovic, 2010) others. This recognition can also inspire an ambition to expand the circle of one's empathy, as advocated by moral philosophers (Singer, 1981). At the same time, some research attests that people sometimes have the opposite goal: There are circumstances in which people would rather feel less empathy. For example, individuals may wish to avoid emotional exhaustion (Cameron, Harris \& Payne, 2015) or elude the anticipated costs of helping the target of their empathy (Shaw, Batson, \& Todd, 1994). Given these intra- and inter-personal consequences of cultivating empathy (Konrath \& Grynberg, 2013), it remains an open question as to whether most people wish they were more, or perhaps less, empathic than they currently are.

\section{Moral Foundations Theory}

Given the theoretical and empirical links between empathy and moral cognition (Eisenberg, 2000; Gleichgerrcht, \& Young, 2013; Graham et al., 2011; Miller, Hannikainen \& Cushman, 2014), we investigated whether volitional changes in empathy also precede shifts in moral values. To examine this question, we draw on an influential theory in moral psychology-the theory of moral foundations (Graham, Haidt \& Nosek, 2009; Iyer, Koleva, Graham, Ditto, \& Haidt, 2012).

Large-scale web surveys have shown that, across a variety of cultures and languages, the content of people's moral norms can be classified using a superstructure of five broad foundations (Graham et al., 2009, 2011). Progressives tend to prioritize two of the five moral foundations (i.e., care and fairness) known as the individualizing foundations, whereas conservatives draw from all five, including three so-called binding foundations (i.e., loyalty to the ingroup, respect for authority, and observance of purity and sanctity standards). People's pattern of moral foundations can also help to explain their attitudes toward various ethical controversies, such as animal testing and euthanasia, and policy debates, e.g., regarding immigration or gun control (Koleva, Graham, Iyer, Ditto \& Haidt, 2012).

Longitudinal studies have revealed substantial fluctuation in people's endorsement of the moral 
foundations over time (Hatemi et al., 2019; Smith, Alford, Hibbing, Martin, \& Hatemi, 2016), which can be predicted by prior assessments of their ideology (i.e., conservatism predicts higher endorsement of binding foundations over time). In contrast, fluctuation in political ideology is more limited and cannot, to the same degree, be predicted by prior measurements of moral foundations. Hatemi and colleagues (2019) interpret this pattern of results as evidence that an individual's political ideology partly determines their moral outlook.

Yet, liberals' prioritization of other-focused values - such as care and fairness - may arise not solely through conformity to ideology, but could also stem from a greater propensity to feel empathy. Empathy predicts the selective moralization of individualizing foundations (Graham et al., 2011); and self-identified leftists across cultures report greater (Hasson, Tamir, Brahms, Cohrs, \& Halperin, and more indiscriminate (Waytz, Iyer, Young, Haidt, \& Graham, 2019) empathy. Thus, it is possible that cultivating an empathic disposition leads to a corresponding shift in moral values, toward a characteristically liberal moral code.

\section{Overview of the Present Study}

In the current work, we examined three related questions using intensive longitudinal methods: (1) Do people want to change their levels of empathic concern and perspective-taking? (2) Do these empathy-related change goals predict subsequent growth in empathic concern and perspective-taking across time? (3) Do people's empathy-related change goals predict longitudinal shifts in their moral foundations? At the beginning of the study, participants reported whether, and how, they desired to change with respect to empathic concern and perspective-taking. Then, over the span of fifteen weeks, we repeatedly assessed their trait levels of empathic concern and perspective-taking, as well as their moral foundations.

\section{Method}

The current study was part of a larger project examining goal setting and volitional changes in personality characteristics (see Hudson et al., 2019 for complete study details). An abridged dataset containing the relevant variables and analysis scripts for this project is available on the Open Science Framework at https://osf.io/ev4h3/.

\section{Participants}

Participants were students in personality psychology courses at the University of Illinois at UrbanaChampaign (UIUC) and Michigan State University (MSU). Data were collected during one semester and sample size was determined by the total enrollment in participating classes; thus, there was no $a$ 
priori stopping rule. A total of 414 participants provided at least one wave of data. At Time 1, the sample was $76 \%$ female with an average age of 20.3 years $(S D=1.70$ years $)$. Sixty six percent of the sample identified as White, $19 \%$ as Asian, $9 \%$ as Black, $7 \%$ as Hispanic, 3\% as Asian Indian, 2\% as Middle Eastern, and $<1 \%$ as Native American, and Pacific Islander.

On average, participants provided 11.4 waves of data $(S D=4.50)$, with $396,359,300$, and 179 participants providing data at Times 2, 5, 10, and 15, respectively. A linear regression predicting number of complete waves based on first-wave measures revealed minimal systematic attrition (omnibus model: $\left.F(6,407)=1.18, p=.32, r^{2}=.017\right)$ : None of the empathy $(p s>.20)$, change goals $(p s>.20)$, or moral foundations $(p s>.10)$ measures predicted number of complete waves.

\section{Measures}

We report all measures and manipulations relevant to the present research question. Indices of internal consistency (Cronbach's $\alpha$ ) were calculated based on Wave 1 data.

\section{Empathy}

Participants completed the empathic concern and perspective-taking subscales of the Interpersonal Reactivity Index (IRI; Davis, 1983). The seven-item empathic concern subscale reflects a person's reaction to others' suffering ("I often have tender, concerned feelings for people less fortunate than me;" $\alpha=.74)$. The seven-item perspective-taking subscale reflects a person's tendency to imagine others' points of view ("I sometimes try to understand my friends better by imagining how things look from their perspective;" $\alpha=.74$ ). Participants rated each item on a scale ranging from 1: "Does not describe me well" to 5: "Describes me very well".

\section{Empathy Change Goals}

At the first assessment point only, participants were provided with modified versions of the empathic concern and perspective-taking subscales of the IRI. Both subscales were reworded to reflect an individual's desire to change on empathic concern and perspective-taking (e.g., "I want to be someone who looks at everybody's side of a disagreement before I make a decision"). Adaptations of the IRI were based on previous research that adapted personality measures to assess change goals using similar techniques (e.g., Hudson \& Roberts, 2014). Participants rated the extent to which they desired change on each item on a scale ranging from -2: "Much less than I currently am" to 2: "Much more than I currently am" (with 0: "I do not want to change in this regard" as the midpoint). Thus, participants could report goals to decrease, increase, or stay the same with respect to each item in the scale. The items were averaged such that higher values reflected a greater desire to increase empathic concern $(\alpha=.60)$ and perspective-taking $(\alpha=.83)$. 


\section{Moral Foundations}

We administered the 20-item short form of the Moral Foundations Questionnaire (Graham et al., 2009). Each of the five moral foundations was measured with four items: care/harm $(\alpha=.55)$, fairness/cheating $(\alpha=.56)$, loyalty/betrayal $(\alpha=.57)$, authority/subversion $(\alpha=.60)$, and sanctity/degradation $(\alpha=.61)$. Participants responded to each question on a scale ranging from 1: "Not at all relevant"/"Strongly disagree" to 5: "Extremely relevant"/"Strongly agree".

Overall, indices of moral foundations revealed poor reliability. Some past research has shown that a two-factor solution, distinguishing individualizing (i.e., harm and fairness) from binding (i.e., loyalty, authority, and purity) foundations, also emerges in exploratory factor analyses (Graham et al., 2011). In our linear growth analyses, we employ measures of individualizing $(\alpha=.68)$ and binding $(\alpha=.79)$ foundations, to ensure satisfactory reliability and provide a more parsimonious test of our hypotheses.

\section{Demographic Information}

At the first assessment point only, participants provided demographic information, including their birthday, gender, racial and ethnic identification, and political orientation.

\section{Procedure}

At the beginning of the college semester, participants were provided with a link to the study website and registered an account to participate. Upon registration, participants completed the empathy change goals and wave 1 measures. Participants were instructed to complete one wave of the study per week for the 15-week semester. At every wave, participants provided self-report ratings of their moral foundations and empathy.

\section{Analysis}

The results of our analyses are presented in two separate sections below. First, we report crosssectional analyses of respondents' information at the time of registration (e.g., whether participants wanted to become more empathic). Second, we report linear growth models to evaluate the longitudinal association between empathy change goals and changes in both self-reported empathy and moral foundations. Growth curve models were estimated with the lme4 package (Bates, Maechler, Bolker, \& Walker, 2015) in $R$ version 3.6.2. $P$ values were calculated using the Satterthwaite method in lmerTest (Kuznetsova, Brockhoff, \& Christensen, 2017).

\section{Results}




\section{First Wave Analyses}

Descriptive statistics and correlations at Wave 1 are displayed in Table 1. (See also Supplementary Table 1 for the five-factor approach to moral foundations).

\section{Empathy}

Replicating past work (Iyer et al., 2012; Tamir et al., 2018), liberals reported greater empathic concern $(r[414]=.24,95 \% \mathrm{CI}[.15, .33], p<.001)$ and somewhat greater perspective-taking, $(r[414]$ $=.10,95 \% \mathrm{CI}[.01, .20], p=.034)$ than did conservatives. We also observed gender (Welch's $t[157.5]$ $=4.65, p<.001, d=0.56,95 \%$ CI $[0.33,0.79])$ and age $(r[398]=-.13,95 \%$ CI $[-.23,-.04], p=.007)$ differences in empathic concern, but not in perspective-taking (Gender: Welch's $t[157.5]=0.09, p=$ $.93, d=0.01,95 \%$ CI $[-0.21,0.24]$; Age: $r[398]=-.02,95 \%$ CI $[-.12, .08], p=.65)$. Specifically, women and younger participants reported greater empathic concern than did men and older participants respectively.

Table 1. Means, standard deviations, and correlations with confidence intervals: First-wave data.

\begin{tabular}{|c|c|c|c|c|c|c|c|c|}
\hline & $\mathbf{M}$ & SD & 1 & 2 & 3 & 4 & 5 & 6 \\
\hline 1.Perspective-taking & 3.76 & 0.55 & - & & & & & \\
\hline 2.Empathic concern & 3.90 & 0.52 & $\begin{array}{c}.47 * * \\
{[.39, .54]}\end{array}$ & - & & & & \\
\hline $\begin{array}{l}\text { 3.Perspective-taking } \\
\text { change goals }\end{array}$ & 0.57 & 0.48 & $\begin{array}{c}-.17 * * \\
{[-.26,-.08]}\end{array}$ & $\begin{array}{c}.04 \\
{[-.05, .14]}\end{array}$ & - & & & \\
\hline $\begin{array}{l}\text { 4.Empathic concern } \\
\text { change goals }\end{array}$ & 0.24 & 0.37 & $\begin{array}{c}-.05 \\
{[-.15, .05]}\end{array}$ & $\begin{array}{c}-.03 \\
{[-.12, .07]}\end{array}$ & $\begin{array}{c}.51^{* *} \\
{[.43, .57]}\end{array}$ & - & & \\
\hline $\begin{array}{l}\text { 5.Individualizing } \\
\text { moral foundations }\end{array}$ & 3.92 & 0.46 & $\begin{array}{c}.27 * * \\
{[.18, .36]}\end{array}$ & $\begin{array}{c}.52 * * \\
{[.44, .58]}\end{array}$ & $\begin{array}{c}.15 * * \\
{[.06, .24]}\end{array}$ & $\begin{array}{c}.11^{*} \\
{[.01, .20]}\end{array}$ & - & \\
\hline $\begin{array}{l}\text { 6. Binding moral } \\
\text { foundations }\end{array}$ & 3.15 & 0.55 & $\begin{array}{c}-.14 * * \\
{[-.23,-.04]}\end{array}$ & $\begin{array}{c}-.06 \\
{[-.16, .03]}\end{array}$ & $\begin{array}{c}-.03 \\
{[-.12, .07]}\end{array}$ & $\begin{array}{c}-.00 \\
{[-.10, .19]}\end{array}$ & $\begin{array}{c}-.00 \\
{[-.10, .10]}\end{array}$ & - \\
\hline
\end{tabular}

Note. $*$ indicates $p<.05 ; * *$ indicates $p<.01$. Values in square brackets correspond to the $95 \%$ confidence interval for each correlation.

\section{Empathic Change Goals}

Participants expressed a desire for empathic development on both dimensions: They wanted to 
become both greater empathizers $(M=0.24,95 \%$ CI [0.20, 0.27], $S D=0.37$; one-sample $t[413]=$ $12.92, d=0.64,95 \% \mathrm{CI}[0.53,0.74])$ and better perspective-takers $(M=0.57,95 \%$ CI $[0.52,0.62]$, $S D=0.48$; one-sample $t[413]=24.25, d=1.19,95 \%$ CI $[1.07,1.32]), p s<.001$. Goals to change in empathy and perspective-taking were themselves correlated $(r[414]=.51,95 \%$ CI $[.43, .57], p<$ $.001)$, but were unrelated to age, gender, or political orientation $(|r| \mathrm{s}<.04, p \mathrm{~s}>.40)$.

Perspective-taking change goals were higher among those who initially reported lower levels of perspective-taking $(r[414]=-.17,95 \%$ CI $[-.26,-.08], p<.001)$. This inverse association between change goals and trait levels (consistently observed in previous research on volitional change; e.g., Hudson, Fraley, et al., 2020) implies the greatest desire for improvement among participants low in perspective-taking. Higher change goals are thus generally interpreted as recognition of weaknesses in the domain of empathy. Yet, it is also possible that reduced change goals reflect greater complacency with one's already high levels of perspective-taking. Future research should explicitly disentangle these possibilities.

Nevertheless, no corresponding pattern emerged for empathic concern: Change goals were not statistically significantly related to initial levels of empathic concern $(r[414]=-.03,95 \%$ CI [-.12, .07], $p=.60$ ) — which calls for further discussion. One possibility for this null result is that people high in empathy are also more enthusiastic about expressing and increasing in empathic concern (see Weisz \& Zaki, 2018)—while low empathizers may be more ambivalent, viewing gains in empathic concern as neither advantageous nor desirable (Bloom, 2017; Sun \& Goodwin, 2020). This would also explain weaker desires to develop empathic concern overall, relative to perspective-taking (paired $t[413]=5.40, p<.001$ ). Alternatively, low empathizers may view growth in empathic concern as less attainable: If beliefs about malleability covary with trait levels, and low empathizers think that they cannot become more empathic (i.e., endorsing the static view of empathy; see Schumann et al., 2014), this would plausibly undermine their goals to change.

\section{Moral Foundations}

In line with past evidence (Graham et al., 2011), liberals expressed greater concern for the individualizing moral foundations $(r[414]=.34,95 \% \mathrm{CI}[.25, .42])$, while conservatives expressed greater concern for the binding moral foundations $(r[414]=-.49,95 \%$ CI $[-.56,-.41])$, both $p$ s < .001. Empathic concern was also linked with individualizing moral values $(r[414]=.52,95 \% \mathrm{CI}$ $[.44, .58], p<.001)$, but not binding moral values $(r[414]=-.06,95 \%$ CI $[-.16, .03], p=.21$; see also Table 1). In turn, perspective-taking correlated positively with individualizing moral foundations $(r[414]=.27,95 \%$ CI $[.18, .36], p<.001)$, and negatively with binding moral foundations $(r[414]=$ $-.14,95 \%$ CI [-.23, -.04], $p=.005)$.

Associations between interpersonal reactivity and moral foundations emerged even when 
controlling for political orientation, as shown in Supplementary Tables 2 and 3. This result indicates that, even once we account for the documented effects of ideology (Hatemi et al., 2019), affective processes independently predict moral foundations.

\section{Longitudinal Analyses}

\section{Do Empathy Change Goals Predict Growth in Empathy?}

For our first series of longitudinal analyses, we assessed whether change goals predicted linear growth in the corresponding traits over the study duration. To this end, we ran mixed-effects regression analyses predicting weekly empathic concern and perspective-taking separately. For example, in one model, we regressed weekly empathic concern on the following set of fixed-effect predictors: (1) time in months, (2) empathic concern change goals, and (3) empathic concern at baseline and $(4,5)$ both two-way interactions between baseline measures and time. These same analyses were completed for perspective-taking (substituting in the corresponding change goals and baseline measures). In the random effects portion of the model, participant and wave were entered as crossed factors. Our focal test (i.e., do desires to become more empathic predict linear changes in empathic concern over time?) concerned the effect of the change goals $\times$ time interaction in each model.

Indeed, empathic concern change goals were associated with subsequent growth in empathic concern $(\beta=0.013,95 \%$ CI [0.001, 0.025], $t=2.10, p=.036$; see Model EC-1 in Table 2). Similarly, perspective-taking scores increased over time as a function of the initial desire to become a better perspective-taker $(\beta=0.018,95 \%$ CI [0.005, 0.030], $t=2.72, p=.007$; see Model PT-1 in Table 3). In other words, people who wanted to increase in empathic concern and/or perspective-taking tended to do so at a faster rate than their peers who did not wish to change those traits (see Figure 1).

Interestingly, mutually controlling for both change goals suggested that perspective-taking (but not empathic concern) change goals predicted increases in both traits (perspective-taking: $\beta=0.026$, 95\% CI [0.011, 0.041], $t=3.42, p=.001$; empathic concern: $\beta=0.019,95 \%$ CI [0.005, 0.033], $t=$ 2.68, $p=.007$; see Models 2 in Tables 2 and 3). Thus, gains in empathic concern are more readily predicted — not intrinsically, by aspiring to feel greater empathy for others - but rather by efforts to see things from others' point of view (consistent with evidence that perspective-taking amplifies empathic reactions; see Lamm et al., 2008). 


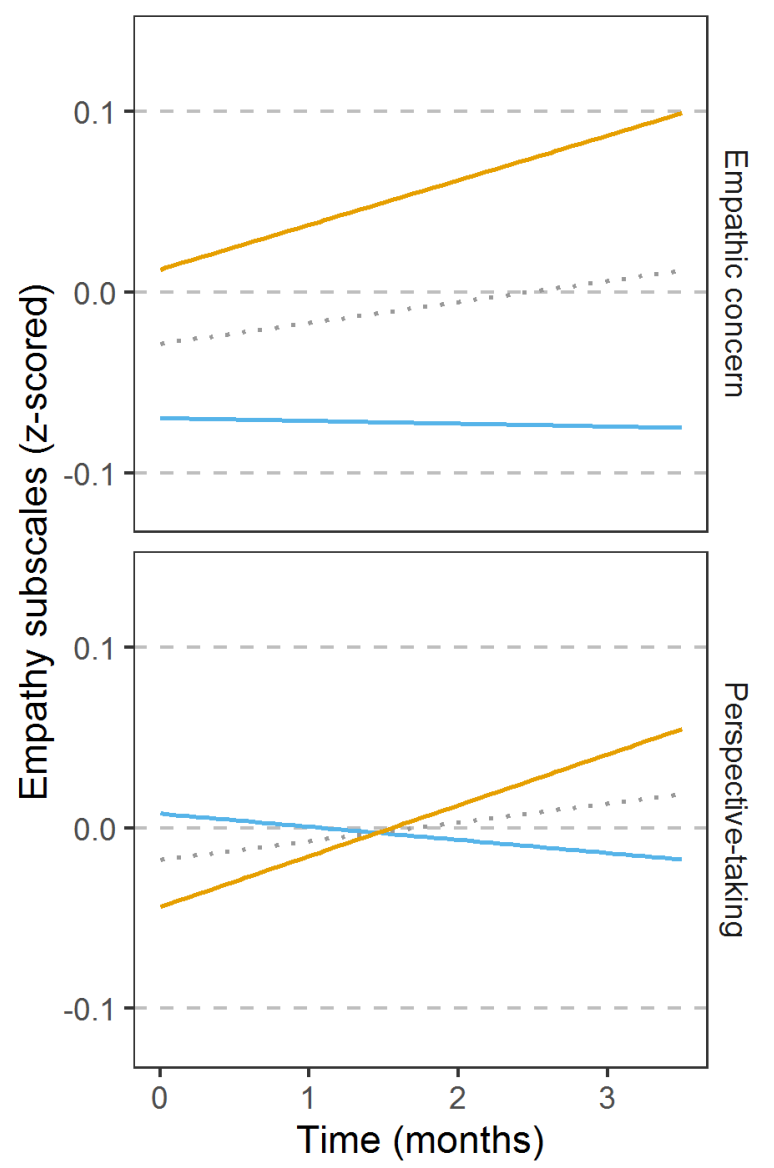

High change goals $(+1 S D)$

Average change goals (Mean)

Low change goals $(-1 \mathrm{SD})$

Figure 1. Empathic concern and perspective-taking by change goals.

Modeling growth in empathy revealed separable effects of baseline levels and change goals. In addition to the positive effects of change goals, trait intercepts negatively predicted slopes-as is often found in longitudinal studies of personality change (Allemand, Zimprich, \& Hertzog, 2007; Little, Bovaird, \& Slegers, 2006). This phenomenon might be expected either due to artifactual causes (i.e., participants' regression to their mean levels of empathy) or substantive reasons (e.g., that people who were initially low in empathy have more 'room' to grow). ${ }^{2}$

2 The artifactual and substantive effects can be dissociated through different forms of centering (Kreft, de Leeuw, \& Aiken, 1995): i.e., on the grand mean (to compare longitudinal effects of differences in baseline scores) versus the subject mean (to account for regression toward the mean across waves). Doing so provides evidence that the negative intercept-slope associations in both $\mathrm{EC}$ and $\mathrm{PT}$ models are primarily due to regression to the subject mean $\left(\mathrm{EC}_{\text {subject }}: \beta=-\right.$ $0.079,95 \%$ CI [-0.086, -0.073], $t=-23.88 ; \mathrm{PT}_{\text {subject }}: \beta=-0.087,95 \%$ CI $[-0.094,-0.080], t=-24.56$, both $\left.p \mathrm{~s}<.001\right)$, and not the grand mean $\left(\mathrm{EC}_{\text {grand }}: \beta=0.008,95 \% \mathrm{CI}[0.001,0.014], t=2.34, p=.019 ; \mathrm{PT}_{\text {grand }}: \beta=0.011,95 \% \mathrm{CI}[0.004\right.$, 
Table 2. Linear growth models predicting empathic concern.

\begin{tabular}{|c|c|c|c|c|c|c|c|c|c|}
\hline & \multicolumn{3}{|c|}{$\begin{array}{c}\text { Model EC-0 } \\
\text { pseudo } r^{2}=.547 ; \mathrm{AIC}=6738\end{array}$} & \multicolumn{3}{|c|}{$\begin{array}{c}\text { Model EC-1 } \\
\text { pseudo } r^{2}=.550 ; \text { AIC }=6732\end{array}$} & \multicolumn{3}{|c|}{$\begin{array}{c}\text { Model EC-2 } \\
\text { pseudo } r^{2}=.551 ; \mathrm{AIC}=6729\end{array}$} \\
\hline Fixed effects & $\begin{array}{c}\beta \\
{[95 \%} \\
C I\end{array}$ & $t$ & $p$ & $\begin{array}{c}\beta \\
{[95 \% \mathrm{CI}]}\end{array}$ & $t$ & $p$ & $\begin{array}{c}\beta \\
{[95 \% \mathrm{CI}]}\end{array}$ & $t$ & $p$ \\
\hline Baseline EC & $\begin{array}{c}0.79 \\
{[0.74,0.85]}\end{array}$ & 28.6 & .000 & $\begin{array}{c}0.79 \\
{[0.74,0.85]}\end{array}$ & 28.7 & .000 & $\begin{array}{c}0.80 \\
{[0.74,0.85]}\end{array}$ & 28.8 & .000 \\
\hline EC change goal & - & - & - & $\begin{array}{c}0.04 \\
{[-0.01,0.09]}\end{array}$ & 1.55 & .12 & $\begin{array}{c}0.06 \\
{[-0.01,0.12]}\end{array}$ & 1.79 & .074 \\
\hline PT change goal & - & - & - & - & - & - & $\begin{array}{c}-0.03 \\
{[-0.09,0.04]}\end{array}$ & -0.86 & .39 \\
\hline Time (months) ${ }^{\#}$ & $\begin{array}{c}0.01 \\
{[-0.01,0.03]}\end{array}$ & 0.99 & .33 & $\begin{array}{c}0.01 \\
{[-0.01,0.03]}\end{array}$ & 1.08 & .29 & $\begin{array}{c}0.01 \\
{[-0.01,0.03]}\end{array}$ & 1.08 & .29 \\
\hline $\begin{array}{l}\text { Baseline EC } \times \\
\text { Time }\end{array}$ & $\begin{array}{c}-0.04 \\
{[-0.05,-0.02]}\end{array}$ & -5.44 & .000 & $\begin{array}{c}-0.03 \\
{[-0.05,-0.02]}\end{array}$ & -5.32 & .000 & $\begin{array}{c}-0.04 \\
{[-0.05,-0.02]}\end{array}$ & -5.55 & .000 \\
\hline $\begin{array}{l}\text { EC change goal } \\
\times \text { Time }\end{array}$ & - & - & - & $\begin{array}{c}0.01 \\
{[0.00,0.03]}\end{array}$ & 2.10 & .036 & $\begin{array}{c}0.00 \\
{[-0.01,0.02]}\end{array}$ & 0.38 & .71 \\
\hline \multirow[t]{2}{*}{$\begin{array}{l}\text { PT change goal } \\
\times \text { Time }\end{array}$} & - & - & - & - & - & - & $\begin{array}{c}0.02 \\
{[0.01,0.03]}\end{array}$ & 2.68 & .007 \\
\hline & $\begin{array}{c}-0.03 \\
{[-0.10,0.04]}\end{array}$ & -0.82 & .41 & $\begin{array}{c}-0.03 \\
{[-0.10,0.04]}\end{array}$ & -0.84 & .41 & $\begin{array}{c}-0.03 \\
{[-0.10,0.04]}\end{array}$ & -0.84 & .40 \\
\hline Random effects & \multicolumn{3}{|c|}{$\sigma$} & \multicolumn{3}{|c|}{ Groups } & \multicolumn{3}{|c|}{ ICC } \\
\hline Participant & \multicolumn{3}{|c|}{0.505} & \multicolumn{3}{|c|}{414} & \multicolumn{3}{|c|}{0.569} \\
\hline Wave & \multicolumn{3}{|c|}{0.041} & \multicolumn{3}{|c|}{15} & \multicolumn{3}{|c|}{0.004} \\
\hline
\end{tabular}

Note. AIC: Akaike information criterion; EC: empathic concern; PT: perspective-taking. Predictors are standardized except where indicated by a pound sign $\left({ }^{\#}\right) . R^{2}$ statistics are for the fixed effects portion of each model. 
Table 3. Linear growth models predicting perspective-taking.

\begin{tabular}{|c|c|c|c|c|c|c|c|c|c|}
\hline & \multicolumn{3}{|c|}{$\begin{array}{c}\text { Model PT-0 } \\
\text { pseudo } r^{2}=.498 ; \text { AIC }=7138\end{array}$} & \multicolumn{3}{|c|}{$\begin{array}{c}\text { Model PT-1 } \\
\text { pseudo } r^{2}=.499 ; \text { AIC }=7135\end{array}$} & \multicolumn{3}{|c|}{$\begin{array}{c}\text { Model PT-2 } \\
\text { pseudo } r^{2}=.501 ; \mathrm{AIC}=7133\end{array}$} \\
\hline Fixed effects & $\begin{array}{c}\beta \\
{[95 \% \mathrm{CI}]}\end{array}$ & $t$ & $p$ & $\begin{array}{c}\beta \\
{[95 \% \mathrm{CI}]}\end{array}$ & $t$ & $p$ & $\begin{array}{c}\beta \\
{[95 \% \mathrm{CI}]}\end{array}$ & $t$ & $p$ \\
\hline Baseline PT & $\begin{array}{c}0.78 \\
{[0.72,0.84]}\end{array}$ & 27.2 & .000 & $\begin{array}{c}0.78 \\
{[0.72,0.83]}\end{array}$ & 26.7 & .000 & $\begin{array}{c}0.78 \\
{[0.72,0.83]}\end{array}$ & 26.7 & .000 \\
\hline PT change goal & - & - & - & $\begin{array}{c}-0.03 \\
{[-0.08,0.03]}\end{array}$ & -0.90 & .37 & $\begin{array}{c}0.02 \\
{[-0.08,0.05]}\end{array}$ & -0.47 & .64 \\
\hline EC change goal & - & - & - & - & - & - & $\begin{array}{c}-0.02 \\
{[-0.08,0.04]}\end{array}$ & -0.60 & .55 \\
\hline Time (months) & $\begin{array}{c}0.01 \\
{[-0.00,0.02]}\end{array}$ & 1.49 & .15 & $\begin{array}{c}0.01 \\
{[-0.00,0.02]}\end{array}$ & 1.49 & .15 & $\begin{array}{c}0.01 \\
{[-0.00,0.02]}\end{array}$ & 1.47 & .16 \\
\hline $\begin{array}{l}\text { Baseline PT } \times \\
\text { Time }\end{array}$ & $\begin{array}{c}-0.05 \\
{[-0.07,-0.04]}\end{array}$ & -8.29 & .000 & $\begin{array}{c}-0.05 \\
{[-0.06,-0.04]}\end{array}$ & -7.57 & .000 & $\begin{array}{c}-0.05 \\
{[-0.06,-0.04]}\end{array}$ & -7.49 & .000 \\
\hline $\begin{array}{l}\text { PT change goal } \\
\times \text { Time }\end{array}$ & - & - & - & $\begin{array}{c}0.02 \\
{[0.01,0.03]}\end{array}$ & 2.72 & .007 & $\begin{array}{c}0.03 \\
{[0.01,0.04]}\end{array}$ & 3.42 & .001 \\
\hline $\begin{array}{l}\text { EC change goal } \\
\times \text { Time }\end{array}$ & - & - & - & - & - & - & $\begin{array}{c}-0.02 \\
{[-0.03,-0.00]}\end{array}$ & -2.12 & .034 \\
\hline Intercept & $\begin{array}{c}-0.02 \\
{[-0.08,0.04]}\end{array}$ & -0.61 & .54 & $\begin{array}{c}-0.02 \\
{[-0.08,0.04]}\end{array}$ & -0.61 & .54 & $\begin{array}{c}-0.02 \\
{[-0.08,0.04]}\end{array}$ & -0.62 & .54 \\
\hline
\end{tabular}

\begin{tabular}{cccc}
\hline Random effects & $\boldsymbol{\sigma}$ & Groups & ICC \\
\hline Participant & 0.528 & 414 & 0.571 \\
\hline Wave & 0.011 & 15 & 0.000 \\
\hline
\end{tabular}

Note. AIC: Akaike information criterion; EC: empathic concern; PT: perspective-taking. Predictors are standardized except where indicated by a pound sign $\left({ }^{\#}\right) . R^{2}$ statistics are for the fixed effects portion of each model.

\section{Do Empathy Change Goals Predict Shifts in Moral Foundations?}

Next, we examined whether empathy-related change goals predicted shifts in moral foundations over time. We conducted a mixed-effects linear regression analysis predicting weekly moral foundation scores with the following fixed-effect predictors: time (in months), change goals, and baseline measures of empathy and moral foundations. All three predictors were allowed to 
interact with time, resulting in three additional terms. In the random effects portion of the model, participant and wave were entered as crossed factors.

For example, in one model (i.e., Model IF-1 in Table 4), we regressed individualizing foundation scores on (1) time, (2) empathic concern change goals, (3) trait empathic concern at baseline, (4) individualizing foundation scores at baseline, (5) the empathic concern change goals by time interaction, (6) trait empathic concern at baseline by time interaction, and (7) the individualizing foundation score by time interaction. This same analysis was then repeated with the perspectivetaking measures (i.e., perspective-taking change goals, and perspective-taking at baseline; see Model IF-2). Our primary prediction in each case concerned the change goals $\times$ time interaction, which captures whether desires to become more empathic (or a better perspective-taker) are associated with changes in individualizing moral foundations over time. Next, these two analyses were repeated for binding foundation scores.

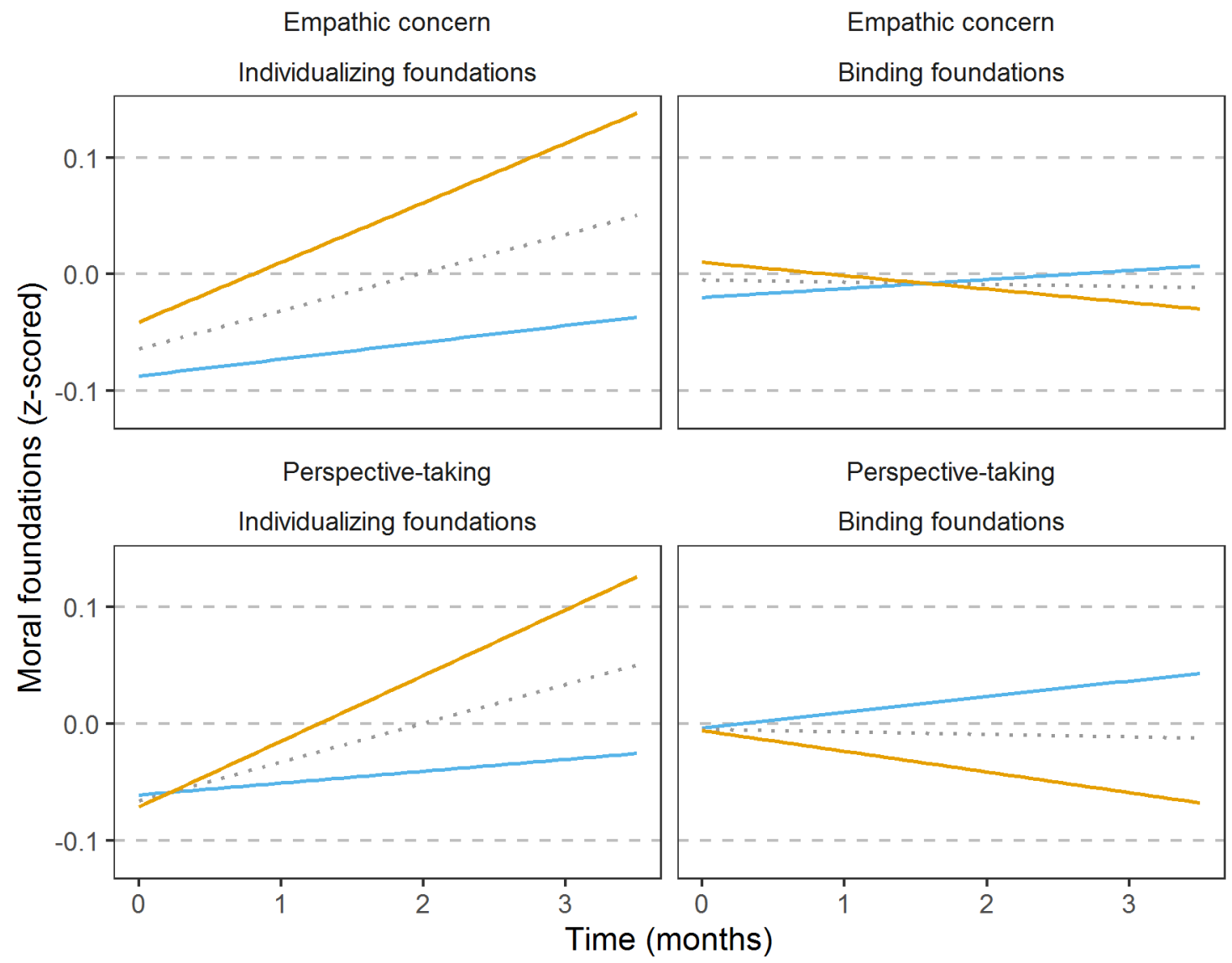

High change goals (+1 SD)

Average change goals (Mean)

Low change goals (-1 SD)

Figure 2. Moral foundations by empathic concern and perspective-taking change goals. 
As shown in Figure 2, desires to become more empathic predicted longitudinal increases in the individualizing foundations $(\beta=0.018,95 \% \mathrm{CI}[0.005,0.032], t=2.69, p=.007)$ and decreases in the binding foundations $(\beta=-0.010,95 \%$ CI $[-0.019,-0.000], t=-2.06, p=.040)$. Similarly, desires to become a better perspective-taker predicted longitudinal increases in individualizing foundations $(\beta=0.023,95 \%$ CI $[0.009,0.037], t=3.33, p=.001)$ and decreases in binding foundations $(\beta=-$ $0.016,95 \%$ CI $[-0.025,-0.006], t=-3.35, p=.001)$. Baseline levels of perspective-taking and empathic concern also predicted longitudinal shifts in individualizing and binding moral foundations, respectively. In other words, empathic individuals appeared to drift toward an individualizing morality over time, and did so at a faster pace if they also sought to become more empathic. These models are described in full in Tables 4 and 5.

Entering both change goals simultaneously in the same model (see Models IF-3 and BF-3) once again revealed more robust effects of perspective-taking. Perspective-taking change goals better predicted longitudinal shifts in both individualizing $(\beta=0.018,95 \% \mathrm{CI}[0.002,0.034], t=2.25, p=$ $.024)$ and binding $(\beta=-0.011,95 \%$ CI $[-0.022,-0.000], t=-1.96, p=.050)$ foundations than did empathic concern change goals (individualizing: $\beta=0.011,95 \% \mathrm{CI}[-0.005,0.026], t=1.34, p=.18$; binding: $\beta=-0.004,95 \%$ CI $[-0.014,0.007], t=-0.65, p=.51)$. However, given the shared variance between both empathy change goals, this result should be interpreted cautiously.

\section{Do Within-Person Changes in Empathy Predict Simultaneous Changes in Moral Foundations?}

Finally, we examined whether within-person changes in empathy were linked with simultaneous changes in the moral foundations. There were moderate within-person correlations between both facets of empathy and the individualizing foundations (empathic concern: $\beta=0.205$, 95\% CI [0.183, 0.226], $t=18.77$; perspective-taking: $\beta=0.146,95 \%$ CI [0.124, 0.168], $t=12.84, p \mathrm{~s}$ $<.001$ ), but not the binding foundations (empathic concern: $\beta=-0.010,95 \% \mathrm{CI}[-0.025,0.006], t=-$ $1.24, p=.22$; perspective-taking: $\beta=0.006$, 95\% CI [-0.009, 0.022], $t=0.77, p=.44)$. This suggests that volitional growth in empathy is associated with simultaneous increases in individualizing moral foundations. 
Table 4. Linear growth models predicting individualizing moral foundations.

\begin{tabular}{|c|c|c|c|c|c|c|c|c|c|}
\hline & \multicolumn{3}{|c|}{$\begin{array}{c}\text { Model IF-1 } \\
\text { pseudo } r^{2}=.493 ; \text { AIC }=7488\end{array}$} & \multicolumn{3}{|c|}{$\begin{array}{c}\text { Model IF-2 } \\
\text { pseudo } r^{2}=.493 ; \text { AIC }=7477\end{array}$} & \multicolumn{3}{|c|}{$\begin{array}{c}\text { Model IF-3 } \\
\text { pseudo } r^{2}=.496 ; \text { AIC }=7476\end{array}$} \\
\hline Fixed effects & $\left.\frac{\beta}{[95 \%} \mathrm{CI}\right]$ & $t$ & $p$ & 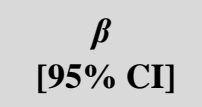 & $t$ & $p$ & $\begin{array}{c}\beta \\
{[95 \%} \\
C I\end{array}$ & $t$ & $p$ \\
\hline Baseline IF & $\begin{array}{c}0.73 \\
{[0.67,0.80]}\end{array}$ & 21.6 & .000 & $\begin{array}{c}0.77 \\
{[0.71,0.83]}\end{array}$ & 25.0 & .000 & $\begin{array}{c}0.74 \\
{[0.67,0.80]}\end{array}$ & 21.6 & .000 \\
\hline Baseline EC & $\begin{array}{c}0.07 \\
{[0.01,0.14]}\end{array}$ & 2.18 & .012 & - & - & - & $\begin{array}{c}0.08 \\
{[0.00,0.15]}\end{array}$ & 2.07 & .039 \\
\hline Baseline PT & - & - & - & $\begin{array}{c}0.03 \\
{[-0.04,0.09]}\end{array}$ & 0.84 & .40 & $\begin{array}{c}-0.00 \\
{[-0.07,0.06]}\end{array}$ & -0.13 & .90 \\
\hline EC change goal & $\begin{array}{c}0.02 \\
{[-0.03,0.08]}\end{array}$ & 0.82 & .41 & - & - & - & $\begin{array}{c}0.04 \\
{[-0.03,0.10]}\end{array}$ & 1.10 & .27 \\
\hline PT change goal & - & - & - & $\begin{array}{c}-0.01 \\
{[-0.06,0.05]}\end{array}$ & -0.17 & .87 & $\begin{array}{c}-0.03 \\
{[-0.10,0.04]}\end{array}$ & -0.80 & .42 \\
\hline Time (months) ${ }^{\#}$ & $\begin{array}{c}0.03 \\
{[0.01,0.06]}\end{array}$ & 2.87 & .013 & $\begin{array}{c}0.03 \\
{[0.01,0.06]}\end{array}$ & 2.94 & .011 & $\begin{array}{c}0.03 \\
{[0.01,0.06]}\end{array}$ & 3.08 & .008 \\
\hline $\begin{array}{l}\text { Baseline IF } \times \\
\text { Month }\end{array}$ & $\begin{array}{c}-0.05 \\
{[-0.07,-0.04]}\end{array}$ & -6.59 & .000 & $\begin{array}{c}-0.06 \\
{[-0.08,-0.05]}\end{array}$ & -8.25 & .000 & $\begin{array}{c}-0.06 \\
{[-0.07,-0.04]}\end{array}$ & -6.97 & .000 \\
\hline $\begin{array}{l}\text { Baseline EC } \times \\
\text { Month }\end{array}$ & $\begin{array}{c}0.00 \\
{[-0.01,0.02]}\end{array}$ & 0.57 & .57 & - & - & - & $\begin{array}{c}-0.01 \\
{[-0.03,0.01]}\end{array}$ & -1.36 & .17 \\
\hline $\begin{array}{l}\text { Baseline PT } \times \\
\text { Month }\end{array}$ & - & - & - & $\begin{array}{c}0.03 \\
{[0.02,0.04]}\end{array}$ & 4.04 & .000 & $\begin{array}{c}0.03 \\
{[0.02,0.05]}\end{array}$ & 4.15 & .000 \\
\hline $\begin{array}{l}\text { EC change goal } \\
\times \text { Month }\end{array}$ & $\begin{array}{c}0.02 \\
{[0.01,0.03]}\end{array}$ & 2.69 & .007 & - & - & - & $\begin{array}{c}0.01 \\
{[-0.01,0.03]}\end{array}$ & 1.34 & .18 \\
\hline $\begin{array}{l}\text { PT change goal } \\
\times \text { Month }\end{array}$ & - & - & - & $\begin{array}{c}0.02 \\
{[0.01,0.04]}\end{array}$ & 3.33 & .001 & $\begin{array}{c}0.02 \\
{[0.00,0.03]}\end{array}$ & 2.25 & .024 \\
\hline Intercept & $\begin{array}{c}-0.06 \\
{[-0.13,0.01]}\end{array}$ & -1.78 & .082 & $\begin{array}{c}-0.07 \\
{[-0.14,0.00]}\end{array}$ & -1.84 & .072 & $\begin{array}{c}-0.07 \\
{[-0.14,0.00]}\end{array}$ & -1.88 & .066 \\
\hline Random effects & & $\sigma$ & & & ups & & & & \\
\hline Participant & & & & & & & & & \\
\hline Wave & & & & & & & & & \\
\hline
\end{tabular}

Note. AIC: Akaike information criterion; EC: empathic concern; PT: perspective-taking. Predictors are standardized except where indicated by a pound sign $\left(^{\#}\right) . R^{2}$ statistics are for the fixed effects portion of each model. 
Table 5. Linear growth models predicting binding moral foundations.

\begin{tabular}{|c|c|c|c|c|c|c|c|c|c|}
\hline \multirow[b]{2}{*}{ Fixed effects } & \multicolumn{3}{|c|}{$\begin{array}{c}\text { Model BF-1 } \\
\text { pseudo } r^{2}=.686 ; \mathrm{AIC}=4053\end{array}$} & \multicolumn{3}{|c|}{$\begin{array}{c}\text { Model BF-2 } \\
\text { pseudo } r^{2}=.684 ; \text { AIC }=4061\end{array}$} & \multicolumn{3}{|c|}{$\begin{array}{c}\text { Model BF-3 } \\
\text { pseudo } r^{2}=.687 ; \mathrm{AIC}=4056\end{array}$} \\
\hline & $\begin{array}{c}\beta \\
{[95 \% \mathrm{CI}]}\end{array}$ & $t$ & $p$ & $\begin{array}{c}\beta \\
{[95 \% \mathrm{CI}]}\end{array}$ & $t$ & $p$ & $\begin{array}{c}\beta \\
{[95 \%} \\
-C I]\end{array}$ & $t$ & $p$ \\
\hline Baseline BF & $\begin{array}{c}0.82 \\
{[0.78,0.87]}\end{array}$ & 34.8 & .000 & $\begin{array}{c}0.82 \\
{[0.78,0.87]}\end{array}$ & 34.3 & .000 & $\begin{array}{c}0.81 \\
{[0.76,0.85]}\end{array}$ & 35.5 & .000 \\
\hline Baseline EC & $\begin{array}{c}-0.03 \\
{[-0.07,0.02]}\end{array}$ & -1.05 & .30 & - & - & - & $\begin{array}{c}-0.02 \\
{[-0.097,0.04]}\end{array}$ & -0.64 & .53 \\
\hline Baseline PT & - & - & - & $\begin{array}{c}-0.02 \\
{[-0.07,0.03]}\end{array}$ & -0.94 & .35 & $\begin{array}{c}-0.02 \\
{[-0.07,0.04]}\end{array}$ & -0.56 & .58 \\
\hline EC change goal & $\begin{array}{c}0.02 \\
{[-0.03,0.06]}\end{array}$ & 0.67 & .51 & - & - & - & $\begin{array}{c}0.02 \\
{[-0.03,0.07]}\end{array}$ & 0.71 & .48 \\
\hline PT change goal & - & - & - & $\begin{array}{c}-0.00 \\
{[-0.05,0.05]}\end{array}$ & -0.05 & .96 & $\begin{array}{c}-0.01 \\
{[-0.06,0.05]}\end{array}$ & -0.33 & .74 \\
\hline Time (months) ${ }^{\#}$ & $\begin{array}{c}-0.00 \\
{[-0.01,0.01]}\end{array}$ & -0.35 & .73 & $\begin{array}{c}-0.00 \\
{[-0.01,0.01]}\end{array}$ & -0.40 & .69 & $\begin{array}{c}-0.00 \\
{[-0.01,0.01]}\end{array}$ & -0.34 & .74 \\
\hline $\begin{array}{l}\text { Baseline } \mathrm{BF} \times \\
\text { Month }\end{array}$ & $\begin{array}{c}-0.01 \\
{[-0.02,0.00]}\end{array}$ & -1.86 & .063 & $\begin{array}{c}-0.01 \\
{[-0.02,0.00]}\end{array}$ & -1.94 & .053 & $\begin{array}{c}-0.01 \\
{[-0.02,0.00]}\end{array}$ & -1.85 & .065 \\
\hline $\begin{array}{l}\text { Baseline EC } \times \\
\text { Month }\end{array}$ & $\begin{array}{c}-0.01 \\
{[-0.03,-0.01]}\end{array}$ & -3.75 & .000 & - & - & - & $\begin{array}{c}-0.02 \\
{[-0.03,-0.01]}\end{array}$ & -3.20 & .001 \\
\hline $\begin{array}{l}\text { Baseline PT } \times \\
\text { Month }\end{array}$ & - & - & - & $\begin{array}{c}-0.01 \\
{[-0.02,0.00]}\end{array}$ & -1.54 & .12 & $\begin{array}{c}0.00 \\
{[-0.01,0.01]}\end{array}$ & 0.35 & .73 \\
\hline $\begin{array}{l}\text { EC change goal } \\
\times \text { Month }\end{array}$ & $\begin{array}{c}-0.01 \\
{[-0.02,-0.00]}\end{array}$ & -2.04 & .040 & - & - & - & $\begin{array}{c}-0.00 \\
{[-0.01,0.01]}\end{array}$ & -0.65 & .51 \\
\hline \multirow[t]{2}{*}{$\begin{array}{l}\text { PT change goal } \\
\times \text { Month }\end{array}$} & - & - & - & $\begin{array}{c}-0.02 \\
{[-0.03,-0.01]}\end{array}$ & -3.35 & .001 & $\begin{array}{c}-0.01 \\
{[-0.02,-0.00]}\end{array}$ & -1.96 & .050 \\
\hline & $\begin{array}{c}-0.01 \\
{[-0.05,0.04]}\end{array}$ & -0.20 & .84 & $\begin{array}{c}-0.01 \\
{[-0.05,0.04]}\end{array}$ & -0.19 & .85 & $\begin{array}{c}-0.01 \\
{[-0.05,0.04]}\end{array}$ & -0.21 & .83 \\
\hline Random effects & \multicolumn{3}{|c|}{$\sigma$} & \multicolumn{3}{|c|}{ Groups } & \multicolumn{3}{|c|}{$I C C$} \\
\hline Participant & \multicolumn{3}{|c|}{0.443} & \multicolumn{3}{|c|}{414} & \multicolumn{3}{|c|}{0.650} \\
\hline Wave & \multicolumn{3}{|c|}{0.012} & \multicolumn{3}{|c|}{15} & \multicolumn{3}{|c|}{0.000} \\
\hline
\end{tabular}

Note. AIC: Akaike information criterion; EC: empathic concern; PT: perspective-taking. Predictors are standardized except where indicated by a pound sign $\left(^{\#}\right) . R^{2}$ statistics are for the fixed effects portion of each model. 


\section{Discussion}

Our study examined the extent to which empathy change goals predicted subsequent changes in empathy and moral foundations. Most participants expressed a desire to develop both the affective (i.e., empathic concern) and cognitive (i.e., perspective-taking) aspects of empathy, and these desires were associated with longitudinal growth on the corresponding traits. In other words, people who wanted to increase in perspective-taking and empathic concern tended to actually do so at a faster rate than their peers who did not wish to change.

Did participants' empathy change goals also predict how their abstract moral values would shift in the span of fifteen weeks? Indeed, those who initially sought to become more empathic, particularly via perspective-taking, experienced more pronounced changes in their moral foundations. Specifically, desires to cultivate empathy preceded increases in the individualizing moral foundations of care and fairness and comparable reductions in the binding moral foundations — while controlling for initial moral attitudes and empathy levels. Finally, we also found that within-person changes in both empathic concern and perspective-taking were correlated with simultaneous changes in moral foundations. Specifically, weekly increases in either facet of empathy predicted growth in individualizing moral foundations, but not decline in binding moral foundations.

When simultaneously considering both empathy change goals, desires to improve in perspective-taking appeared to account for longitudinal change in both facets of empathy and both groups of moral foundations. Doing so rendered the effects of desires to cultivate empathic concern non-significant. Why might the effects of perspective-taking change goals be more robust? First, previous research shows that perspective-taking modulates empathic concern (Batson et al., 1997; Lamm et al., 2008)—whereas the opposite effect has not been found. Thus, perspective-taking change goals may ultimately predict downstream changes in moral judgment and prosocial behavior (Galinsky \& Moskowitz, 2000; Todd et al., 2011), even while affective empathy could play a mediating role (as suggested by the within-person analyses; see also Eisenberg, Zhou, \& Koller, 2001). Additionally, perspective-taking may be more malleable than empathic concern-an assumption that is present in much of the empathy scholarship, including the IRI instrument itself (Davis, 1983). Indeed, evidence for this phenomenon can be seen in Tables 2 and 3. Qualitatively comparing the effect of baseline IRI scores and weekly levels for the corresponding subscale suggests greater stability in empathic concern than in perspective-taking. Finally, it is also important to note that there was a substantial amount of shared variance between empathic concern and perspective-taking goals $(r=.51, p<.001)$. Thus, statistical models in which both were entered as predictors to parcel out variance attributable to each dimension could be compromised by 
collinearity.

Collectively, our findings suggest that people typically want to cultivate greater empathy and that they may be able to find some degree of success in doing so. This aligns with prior studies showing that people can volitionally change their big five personality traits and attachment styles, as well (Hudson, Chopik, \& Briley, 2020; Hudson, Fraley, et al., 2020). Moreover, volitional changes in empathy may have downstream consequences for how people construe morality.

With few exceptions (Hatemi et al., 2017), most research to date has examined moral foundations in a cross-sectional context. However, like many other psychological characteristics, moral foundations are malleable by individual and situational processes that need time to unfold. Here, we found that developing ostensibly separate traits-namely, affective and cognitive empathy - predicted simultaneous systematic shifts in moral foundations. Thus, some of people's moral migration in adulthood may be attributable to a volitional emphasis on adopting others' perspectives (see also Chakroff, Dungan, \& Young, 2013; Hannikainen, Miller \& Cushman, 2017). Such an insight leads to further questions about how and why moral foundations, and political orientations more generally, might evolve over time.

Beyond basic science, the theory of moral foundations aspires to the applied, societal goal of appeasing partisan intolerance (Haidt, 2012). The reasoning is that, furnished with scientific insights into the origin of their moral disagreements, liberals and conservatives might become more openminded and develop a mutual appreciation for each other's' point of view.

Yet, in our study, improvements in perspective-taking did not appear to have this symmetric influence. Namely, volitional growth in perspective-taking predicted increases in a liberal worldview, while also predicting decreases in characteristically conservative moral values, such as loyalty to the ingroup, and respect for authority, and bodily purity — perhaps due to a recognition that instilling these moral norms may simultaneously cause detriment to others' welfare (Hannikainen \& Rosas, 2019, Royzman, Landy \& Goodwin, 2014). As such, our findings cast some doubt on the idea that widespread perspective-taking efforts would yield a pluralistic attitude toward different moral codes. Rather, on the basis of our data, broad gains in perspective-taking might simply nudge individuals and political groups leftward on the moral spectrum.

\section{Constraints on Generality}

It is important to note that our study was conducted with relatively homogeneous samples of undergraduate students. Published reports contrasting representative and convenience samples have shown largely convergent results across sampling methods-at least with regard to moral 
foundations (Hatemi et al., 2017) and empathy (O'Brien et al., 2013). Meanwhile, other research reveals national and regional variation in the psychological profiles of liberals and conservatives (Malka, Soto, Inzlicht, \& Lelkes, 2014), and in the prevalence of dispositional empathy (Bach, Defever, Chopik, \& Konrath, 2017; Chopik, O'Brien \& Konrath, 2017). As a result, there is some degree of uncertainty in whether our primary findings would generalize across cultures and settings.

\section{Limitations and Future Directions}

One limitation of the present study is that we relied exclusively on self-report data. Future studies should also include observer reports to corroborate the observed trait changes (e.g., Paulhus \& Vazire, 2007; Sun \& Goodwin, 2020).

Second, our study relied exclusively upon correlational methods. Thus, we cannot soundly conclude that changes in empathy caused shifts in moral foundations.

Third, the longitudinal effects we documented were small. A standard deviation difference in perspective-taking goals predicted change no greater than \pm 0.02 standardized units per month on measures of moral foundations (although these effect sizes are in the realm of what is found in similar studies on volitional change; see Hudson, Fraley, et al., 2020). Thus, future work should seek to replicate these effects using behavioral measures, and engage participants in tasks that invite them to adopt others' perspective (see Hudson et al., 2018) to induce and record change.

Fourth, it is possible that regular assessment of a particular trait may accelerate change in ways that do not resemble personal development in naturalistic contexts. In particular, weekly re-test may have reminded participants of their change goals - and without these reminders they may not have undergone comparable trait change (see Baranski, Gray, Morse, \& Dunlop, 2020).

\section{Conclusion}

Perspective-taking has been characterized as the ability to imaginatively transpose ourselves into others' shoes. Taking another's perspective awakens concern for their wellbeing, even in the absence of visible distress (Vaish et al., 2009). In turn, the present study suggests that desires to develop perspective-taking abilities may systematically nudge us toward the individualizing moral values of care and fairness-converging with recent evidence that the simulation and valuation of patient welfare undergird individualizing, but not binding, moral concerns (Chakroff et al., 2013; Hannikainen et al., 2017). Thus, differences in moral foundations between conservatives and liberals may stem partially from interpersonal affect, including empathy (Hasson et al., 2018; Waytz et al., 2019). Our findings revealed that, across the political spectrum, people express comparable empathic 
change goals - and these goals may be nudging them toward an individualizing morality. Thus, as liberals and conservatives seek to become more empathic, the gulf between the moral foundations they espouse may gradually narrow over time.

\section{References}

Allemand, M., Zimprich, D., \& Hertzog, C. (2007). Cross-sectional age differences and longitudinal age changes of personality in middle adulthood and old age. Journal of Personality, 75(2), 323-358.

Bach, R. A., Defever, A. M., Chopik, W. J., \& Konrath, S. H. (2017). Geographic variation in empathy: A state-level analysis. Journal of Research in Personality, 68, 124-130.

Baranski, E., Gray, J., Morse, P., \& Dunlop, W. (2020). From desire to development? A multi-sample, idiographic examination of volitional personality change. Journal of Research in Personality, 85, 103910.

Baranski, E. N., Morse, P. J., \& Dunlop, W. L. (2017). Lay conceptions of volitional personality change: From strategies pursued to stories told. Journal of Personality, 85, 285-299.

Bates, D., Maechler, M., Bolker, B., \& Walker, S. (2015). Fitting linear mixed-effects models using lme4. Journal of Statistical Software.

Batson, C. D. (2011). Altruism in humans. Oxford University Press, USA.

Batson, C. D., Early, S., \& Salvarani, G. (1997). Perspective taking: Imagining how another feels versus imaging how you would feel. Personality and Social Psychology Bulletin.

Blair, R. J. R. (1995). A cognitive developmental approach to morality: Investigating the psychopath. Cognition.

Bloom, P. (2017). Against empathy: The case for rational compassion. Random House.

Cameron, C. D., Harris, L. T., \& Payne, B. K. (2016). The emotional cost of humanity: Anticipated exhaustion motivates dehumanization of stigmatized targets. Social Psychological and Personality Science, 7(2), 105-112.

Cameron, C. D., \& Payne, B. K. (2011). Escaping affect: how motivated emotion regulation creates insensitivity to mass suffering. Journal of personality and social psychology, 100(1), 1.

Chakroff, A., Dungan, J., \& Young, L. (2013). Harming ourselves and defiling others: What determines a moral domain?. PloS one.

Chopik, W. J., O'Brien, E., \& Konrath, S. H. (2017). Differences in empathic concern and perspective taking across 63 countries. Journal of Cross-Cultural Psychology, 48(1), 23-38.

Colby, A., Kohlberg, L., Gibbs, J., Lieberman, M., Fischer, K., \& Saltzstein, H. D. (1983). A longitudinal study of moral judgment. Monographs of the society for research in child development, 1-124.

Cushman, F. (2013). Action, outcome, and value: A dual-system framework for morality. Personality and Social Psychology Review.

Davis, M. H. (1983). Measuring individual differences in empathy: Evidence for a multidimensional approach. Journal of Personality and Social Psychology.

Decety, J., \& Lamm, C. (2006). Human empathy through the lens of social neuroscience. The Scientific World Journal, 6, 1146-1163.

Eisenberg, N. (2000). Emotion, regulation, and moral development. Annual Review of Psychology.

Eisenberg, N., Cumberland, A., Guthrie, I. K., Murphy, B. C., \& Shepard, S. A. (2005). Age changes in prosocial responding and moral reasoning in adolescence and early adulthood. Journal of Research on Adolescence.

Eisenberg, N., Miller, P. A., Shell, R., McNalley, S., \& Shea, C. (1991). Prosocial development in adolescence: A longitudinal study. Developmental Psychology, 27(5), 849. 
Eisenberg, N., Zhou, Q., \& Koller, S. (2001). Brazilian adolescents' prosocial moral judgment and behavior: Relations to sympathy, perspective taking, gender-role orientation, and demographic characteristics. Child Development.

Galinsky, A. D., \& Moskowitz, G. B. (2000). Perspective-taking: decreasing stereotype expression, stereotype accessibility, and in-group favoritism. Journal of Personality and Social Psychology.

Gleichgerrcht, E., \& Young, L. (2013). Low levels of empathic concern predict utilitarian moral judgment. PloS one.

Graham, J., Haidt, J., \& Nosek, B. A. (2009). Liberals and conservatives rely on different sets of moral foundations. Journal of Personality and Social Psychology.

Graham, J., Nosek, B. A., Haidt, J., Iyer, R., Koleva, S., \& Ditto, P. H. (2011). Mapping the moral domain. Journal of Personality and Social Psychology.

Haidt, J. (2007). The new synthesis in moral psychology. Science, 316(5827), 998-1002.

Haidt, J. (2012). The righteous mind: Why good people are divided by politics and religion. Vintage.

Hannikainen, I. R., Miller, R. M., \& Cushman, F. A. (2017). Act versus impact: Conservatives and liberals exhibit different structural emphases in moral judgment. Ratio, 30(4), 462-493.

Hannikainen, I. R., \& Rosas, A. (2019). Rationalization and reflection differentially modulate prior attitudes toward the purity domain. Cognitive Science, 43(6), e12747.

Hasson, Y., Tamir, M., Brahms, K. S., Cohrs, J. C., \& Halperin, E. (2018). Are liberals and conservatives equally motivated to feel empathy toward others? Personality and Social Psychology Bulletin.

Hatemi, P. K., Crabtree, C., \& Smith, K. B. (2019). Ideology justifies morality: Political beliefs predict moral foundations. American Journal of Political Science, 63(4), 788-806.

Hennecke, M., Bleidorn, W., Denissen, J. J. A., \& Wood, D. (2014). A three-part framework for self-regulated personality development across adulthood. European Journal of Personality, 28, 289-299.

Hudson, N. W., Briley, D. A., Chopik, W. J., \& Derringer, J. (2019). You have to follow through: Attaining behavioral change goals predicts volitional personality change. Journal of Personality and Social Psychology, 117(4), 839.

Hudson, N. W., Chopik, W. J., \& Briley, D. A. (2020). Volitional change in adult attachment: Can people who want to become less anxious and avoidant move closer toward realizing those goals? European Journal of Personality, in press.

Hudson, N. W., \& Fraley, R. C. (2015). Volitional personality trait change: Can people choose to change their personality traits?. Journal of Personality and Social Psychology.

Hudson, N. W., \& Fraley, R. C. (2016). Do people's desires to change their personality traits vary with age? An examination of trait change goals across adulthood. Social Psychological and Personality Science, 7, 847-856.

Hudson, N. W., Fraley, R. C., Chopik, W. J., \& Briley, D. A. (2020). Change goals robustly predict trait growth: A mega-analysis of a dozen intensive longitudinal studies examining volitional change. Social Psychological and Personality Science, in press.

Hudson, N. W., \& Roberts, B. W. (2014). Goals to change personality traits: Concurrent links between personality traits, daily behavior, and goals to change oneself. Journal of Research in Personality.

Iyer, R., Koleva, S., Graham, J., Ditto, P., \& Haidt, J. (2012). Understanding libertarian morality: The psychological dispositions of self-identified libertarians. PloS one.

Keysers, C., \& Gazzola, V. (2014). Dissociating the ability and propensity for empathy. Trends in Cognitive Sciences, 18(4), 163-166.

Koleva, S. P., Graham, J., Iyer, R., Ditto, P. H., \& Haidt, J. (2012). Tracing the threads: How five moral concerns (especially Purity) help explain culture war attitudes. Journal of Research in Personality, 46(2), 184-194.

Konrath, S., \& Grynberg, D. (2013). The positive (and negative) psychology of empathy. In D. Watt \& J. Panksepp (Eds.), The neurobiology and psychology of empathy. Hauppauge, NY: Nova Biomedical 
Books.

Kreft, I. G., De Leeuw, J., \& Aiken, L. S. (1995). The effect of different forms of centering in hierarchical linear models. Multivariate behavioral research, 30(1), 1-21.

Kuznetsova, A., Brockhoff, P. B., \& Christensen, R. H. B. (2017). lmerTest package: tests in linear mixed effects models. Journal of statistical software, 82(13).

Lamm, C., Porges, E. C., Cacioppo, J. T., \& Decety, J. (2008). Perspective taking is associated with specific facial responses during empathy for pain. Brain Research.

Little, T. D., Bovaird, J. A., \& Slegers, D. W. (2006). Methods for the Analysis of Change. In D. K., Mroczek \& T. D. Little (Eds.), Handbook of personality development. (pp. 181-211). Lawrence Erlbaum Associates Publishers.

Magidson, J. F., Roberts, B. W., Collado-Rodriguez, A., \& Lejuez, C. W. (2014). Theory-driven intervention for changing personality: Expectancy value theory, behavioral activation, and conscientiousness. Developmental Psychology, 50, 1442-1450.

Malka, A., Soto, C. J., Inzlicht, M., \& Lelkes, Y. (2014). Do needs for security and certainty predict cultural and economic conservatism? A cross-national analysis. Journal of Personality and Social Psychology, 106(6), 1031.

Marsh, A. A., Stoycos, S. A., Brethel-Haurwitz, K. M., Robinson, P., VanMeter, J. W., \& Cardinale, E. M. (2014). Neural and cognitive characteristics of extraordinary altruists. Proceedings of the National Academy of Sciences, 111(42), 15036-15041.

Meffert, H., Gazzola, V., Den Boer, J. A., Bartels, A. A., \& Keysers, C. (2013). Reduced spontaneous but relatively normal deliberate vicarious representations in psychopathy. Brain, 136(8), 2550-2562.

Miller, R. M., Hannikainen, I. R., \& Cushman, F. A. (2014). Bad actions or bad outcomes? Differentiating affective contributions to the moral condemnation of harm. Emotion, 14(3), 573.

Miller, T. J., Baranski, E. N., Dunlop, W. L., \& Ozer, D. J. (2019). Striving for change: The prevalence and correlates of personality change goals. Journal of Research in Personality, 80, 10-16.

Mitchell, J. P., Macrae, C. N., \& Banaji, M. R. (2006). Dissociable medial prefrontal contributions to judgments of similar and dissimilar others. Neuron, 50(4), 655-663.

O'Brien, E., Konrath, S. H., Grühn, D., \& Hagen, A. L. (2013). Empathic concern and perspective taking: Linear and quadratic effects of age across the adult life span. The Journals of Gerontology, Series B: Psychological Sciences and Social Sciences.

Oh, J., Chopik, W. J., Konrath, S., \& Grimm, K. J. (2019). Longitudinal changes in empathy across the life span in six samples of human development. Social Psychological and Personality Science, 1948550619849429.

Paulhus, D. L., \& Vazire, S. (2007). The self-report method. Handbook of research methods in personality psychology, 1, 224-239.

Preston, S. D., \& De Waal, F. B. (2002). Empathy: Its ultimate and proximate bases. Behavioral and Brain Sciences.

Prochaska, J. O., DiClemente, C. C., \& Norcross, J. C. (1993). In search of how people change: Applications to addictive behaviors. Addictions Nursing Network, 5(1), 2-16.

Roberts, B. W. (2018). A revised sociogenomic model of personality traits. Journal of Personality, 86, $23-35$.

Robinson, O. C., Noftle, E. E., Guo, J., Asadi, S., \& Zhang, X. (2015). Goals and plans for Big Five personality trait change in young adults. Journal of Research in Personality, 59, 31-43.

Royzman, E. B., Landy, J. F., \& Goodwin, G. P. (2014). Are good reasoners more incest-friendly? Trait cognitive reflection predicts selective moralization in a sample of American adults. Judgment and Decision Making.

Schumann, K., Zaki, J., \& Dweck, C. S. (2014). Addressing the empathy deficit: Beliefs about the malleability of empathy predict effortful responses when empathy is challenging. Journal of Personality and Social Psychology, 107(3), 475. 
Shaw, L. L., Batson, C. D., \& Todd, R. M. (1994). Empathy avoidance: Forestalling feeling for another in order to escape the motivational consequences. Journal of Personality and Social Psychology, 67(5), 879-887.

Simons, D. J., Shoda, Y., \& Lindsay, D. S. (2017). Constraints on generality (COG): A proposed addition to all empirical papers. Perspectives on Psychological Science, 12(6), 1123-1128.

Singer, P. (1981). The expanding circle. Oxford: Clarendon Press.

Slovic, P. (2010). If I look at the mass I will never act: Psychic numbing and genocide. In Emotions and risky technologies (pp. 37-59). Springer, Dordrecht.

Smith, K. B., Alford, J. R., Hibbing, J. R., Martin, N. G., \& Hatemi, P. K. (2017). Intuitive ethics and political orientations: Testing moral foundations as a theory of political ideology. American Journal of Political Science, 61(2), 424-437.

Sun, J., \& Goodwin, G. P. (2020). Do people want to be more moral?. Psychological Science, 31(3), 243-257.

Todd, A. R., Bodenhausen, G. V., Richeson, J. A., \& Galinsky, A. D. (2011). Perspective taking combats automatic expressions of racial bias. Journal of Personality and Social Psychology.

Vaish, A., Carpenter, M., \& Tomasello, M. (2009). Sympathy through affective perspective taking and its relation to prosocial behavior in toddlers. Developmental Psychology.

Waytz, A., Iyer, R., Young, L., Haidt, J., \& Graham, J. (2019). Ideological differences in the expanse of the moral circle. Nature Communications, 10(1), 1-12.

Weisz, E., \& Zaki, J. (2018). Motivated empathy: a social neuroscience perspective. Current Opinion in Psychology, 24, 67-71. 
Supplementary Table 1

Correlations between moral foundations, empathy and change goals: Five-factor approach.

\begin{tabular}{|c|c|c|c|c|c|c|}
\hline & M & $\mathrm{SD}$ & Baseline EC & Baseline PT & EC change goals & PT change goals \\
\hline \multirow{2}{*}{ Harm } & \multirow{2}{*}{3.96} & \multirow{2}{*}{0.56} & $.52 * *$ & $.25^{* *}$ & $.12^{*}$ & $.17 * *$ \\
\hline & & & {$[.45, .59]$} & {$[.16, .34]$} & {$[.03, .22]$} & {$[.08, .26]$} \\
\hline \multirow{2}{*}{ Fairness } & \multirow{2}{*}{3.88} & \multirow{2}{*}{0.54} & $.34 * *$ & $.20 * *$ & .06 & .08 \\
\hline & & & {$[.26, .43]$} & {$[.11, .29]$} & {$[-.04, .15]$} & {$[-.01, .18]$} \\
\hline \multirow{2}{*}{ Loyalty } & \multirow{2}{*}{3.13} & \multirow{2}{*}{0.69} & $-.11 *$ & -.07 & -.02 & -.03 \\
\hline & & & {$[-.21,-.02]$} & {$[-.17, .03]$} & {$[-.11, .08]$} & {$[-.13, .06]$} \\
\hline \multirow{2}{*}{ Authority } & \multirow{2}{*}{3.12} & \multirow{2}{*}{0.68} & $-.12 *$ & $-.15 * *$ & -.02 & -.03 \\
\hline & & & {$[-.21,-.02]$} & {$[-.24,-.05]$} & {$[-.11, .08]$} & {$[-.12, .07]$} \\
\hline \multirow{2}{*}{ Purity } & \multirow{2}{*}{3.20} & \multirow{2}{*}{0.66} & .09 & $-.13^{*}$ & .02 & .00 \\
\hline & & & {$[-.01, .18]$} & {$[-.22,-.03]$} & {$[-.07, .12]$} & {$[-.10, .10]$} \\
\hline
\end{tabular}

Note. * indicates $p<.05 ; * *$ indicates $p<.01$. PT: perspective-taking; EC: empathic concern. Values in square brackets correspond to the $95 \%$ confidence interval for each correlation. 
Supplementary Table 2

Regression models predicting individualizing moral foundations: First-wave data.

\begin{tabular}{|c|c|c|c|c|c|c|c|c|c|}
\hline & \multicolumn{3}{|c|}{$\begin{array}{c}\text { Model } 1 \\
r^{2}=.32 ; \text { AIC }=1025\end{array}$} & \multicolumn{3}{|c|}{$\begin{array}{c}\text { Model } 2 \\
r^{2}=.17 ; \text { AIC }=1104\end{array}$} & \multicolumn{3}{|c|}{$\begin{array}{c}\text { Model 2 } \\
r^{2}=.32 ; \text { AIC }=1027\end{array}$} \\
\hline & $\begin{array}{c}\beta \\
{[95 \% \mathrm{CI}]}\end{array}$ & $t$ & $p$ & $\begin{array}{c}\beta \\
{[95 \% \mathrm{CI}]}\end{array}$ & $t$ & $p$ & $\begin{array}{c}\beta \\
{[95 \% \mathrm{CI}]}\end{array}$ & $t$ & $p$ \\
\hline $\begin{array}{l}\text { Empathic } \\
\text { concern }\end{array}$ & $\begin{array}{c}0.46 \\
{[0.38,0.54]}\end{array}$ & 10.9 & .000 & & & & $\begin{array}{c}0.44 \\
{[0.35,0.54]}\end{array}$ & 9.32 & .000 \\
\hline $\begin{array}{l}\text { Perspective- } \\
\text { taking }\end{array}$ & & & & $\begin{array}{c}0.24 \\
{[0.15,0.32]}\end{array}$ & 5.22 & .000 & $\begin{array}{c}0.04 \\
{[-0.05,0.13]}\end{array}$ & 0.76 & .45 \\
\hline $\begin{array}{l}\text { Political } \\
\text { orientation }\end{array}$ & $\begin{array}{c}0.23 \\
{[0.15,0.31]}\end{array}$ & 5.46 & .000 & $\begin{array}{c}0.32 \\
{[0.23,0.41]}\end{array}$ & 7.02 & .000 & $\begin{array}{c}0.23 \\
{[0.15,0.31]}\end{array}$ & 5.47 & .000 \\
\hline Intercept & $\begin{array}{c}0.00 \\
{[-0.08,0.08]}\end{array}$ & 0.00 & 1 & $\begin{array}{c}-0.00 \\
{[-0.09,0.09]}\end{array}$ & 0.00 & 1 & $\begin{array}{c}0.00 \\
{[-0.08,0.08]}\end{array}$ & 0.00 & 1 \\
\hline
\end{tabular}


Supplementary Table 3

Regression models predicting binding moral foundations: First-wave data.

\begin{tabular}{|c|c|c|c|c|c|c|c|c|c|}
\hline & \multicolumn{3}{|c|}{$\begin{array}{c}\text { Model } 1 \\
r^{2}=.25 ; \text { AIC }=1066\end{array}$} & \multicolumn{3}{|c|}{$\begin{array}{c}\text { Model } 2 \\
r^{2}=.25 ; \text { AIC }=1063\end{array}$} & \multicolumn{3}{|c|}{$\begin{array}{c}\text { Model } 3 \\
r^{2}=.26 ; \text { AIC }=1058\end{array}$} \\
\hline & $\begin{array}{c}\beta \\
{[95 \% \mathrm{CI}]}\end{array}$ & $t$ & $p$ & $\begin{array}{c}\beta \\
{[95 \% \mathrm{CI}]}\end{array}$ & $t$ & $p$ & $\begin{array}{c}\beta \\
{[95 \% \mathrm{CI}]}\end{array}$ & $t$ & $p$ \\
\hline $\begin{array}{l}\text { Empathic } \\
\text { concern }\end{array}$ & $\begin{array}{c}0.06 \\
{[-0.03,0.15]}\end{array}$ & 1.37 & .17 & & & & $\begin{array}{c}0.13 \\
{[0.03,0.23]}\end{array}$ & 2.65 & .008 \\
\hline $\begin{array}{l}\text { Perspective- } \\
\text { taking }\end{array}$ & & & & $\begin{array}{c}-0.09 \\
{[-0.17,-0.00]}\end{array}$ & -2.06 & .040 & $\begin{array}{c}-0.15 \\
{[-0.24,-0.05]}\end{array}$ & -3.07 & .002 \\
\hline $\begin{array}{l}\text { Political } \\
\text { orientation }\end{array}$ & $\begin{array}{c}-0.51 \\
{[-0.59,-0.42]}\end{array}$ & -11.4 & .000 & $\begin{array}{c}-0.48 \\
{[-0.57,-0.40]}\end{array}$ & -11.2 & .000 & $\begin{array}{c}-0.51 \\
{[-0.59,-0.42]}\end{array}$ & -11.6 & .000 \\
\hline Intercept & $\begin{array}{c}0.00 \\
{[-0.08,0.08]}\end{array}$ & 0.00 & 1 & $\begin{array}{c}0.00 \\
{[-0.08,0.08]}\end{array}$ & 0.00 & 1 & $\begin{array}{c}0.00 \\
{[-0.08,0.08]}\end{array}$ & 0.00 & 1 \\
\hline
\end{tabular}

